\title{
Body Mass Index as a Patient Selection Criterion for Kidney Transplant
}

Megan Urbanski1 ${ }^{1}$, Salini Inaganti ${ }^{2}$, Chidera Agu ${ }^{1}$, David B. Sarwer ${ }^{2}$, Heather M. Gardiner ${ }^{1}$

${ }^{1}$ Department of Social and Behavioral Sciences, Temple University College of Public Health

2 Temple University College of Public Health

Correspondence: heather.gardiner@temple.edu (Heather M. Gardiner)

There is currently no consensus on the ideal body mass index (BMI) for kidney transplantation, yet an elevated BMI can limit access to transplantation. This study explored the attitudes of kidney transplant professionals regarding BMI as a selection criterion for kidney transplantation. Brief, in-person interviews were conducted at the 2016 American Transplant Congress. Participants were queried on their views regarding kidney transplant eligibility for patients with classes 1, 2, and 3 obesity, as well as their transplant centers' BMI-related policies. Most (88\%) of the 94 participants did not consider class 1 obesity (BMI 30 to < 35) a contraindication to kidney transplantation, with a greater number of participants reluctant to consider patients with class 2 (BMI 35 to $<40)$ or class 3 obesity (BMI $\geq 40)$ for transplantation. Participants' suggested BMI limit was 2.3 points higher than that reported in transplant center policies. Overall, kidney transplant professionals viewed BMI a useful patient selection criterion when considered within the larger context of the patient's clinical picture. Future research should assess outcomes for transplant recipients with varying obesity levels.

\section{Introduction}

Since the first successful kidney transplant was performed in 1954, there has been a persistent disparity in the supply of kidneys available for transplantation and the increasing demand. ${ }^{1,2}$ Today, there are nearly 95,000 individuals waiting for a kidney transplant, while just over 23,400 kidney transplants were performed in the United States last year. ${ }^{1}$ This imbalance has forced the medical community to consider the ethical allocation of these scarce resources. The dilemma has primarily been addressed through the institution of patient selection or eligibility criteria policies and practices. Presently, in the United States, it is at the discretion of every kidney transplant center to define their own patient selection criteria for potential kidney transplant candidates, in the form of indications and contraindications to kidney transplantation.

The rate of obesity in the United States has increased dramatically over the past several decades. Currently, over $40 \%$ of Americans have obesity, having a body mass index (BMI) greater than $30 \mathrm{~kg} / \mathrm{m}^{2} .{ }^{3}$ Another third of Americans have a BMI between 25 and 30, placing them at risk for becoming clinically obese as they age. ${ }^{4}$ Because of the rapidly increasing prevalence of obesity, BMI has emerged as a relevant factor when determining an individual's eligibility for kidney transplantation. The average BMI of patients on dialysis has also been increasing exponentially 
in the past several years. ${ }^{5,6}$ Twenty-four percent of kidney transplant candidates on the waiting list in the United States meet the criteria for class 1 obesity (defined as BMI of 30 to $<35 \mathrm{~kg} / \mathrm{m}^{2}$ ) and more than $14 \%$ meet the criteria for classes 2 or 3 obesity (defined as BMI of 35 to $<40$ $\mathrm{kg} / \mathrm{m}^{2}$ and $\geq 40$, respectively). ${ }^{1,7}$

Some research suggests that patients with obesity have inferior clinical outcomes following kidney transplantation, including decreased patient survival, ${ }^{8}$ delayed graft function, ${ }^{9-13}$ poor wound adhesion, ${ }^{13-18}$ increased graft failure, ${ }^{11,19}$ and an increased risk of diabetes and cardiac disease, ${ }^{20,21}$ compared to patients without obesity. Consequently, some patients with obesity are denied kidney transplantation due to a perceived increased risk of poor outcomes. ${ }^{22}$ Conversely, although some immediate postoperative outcomes are inferior, kidney transplant recipients with obesity have comparable long-term outcomes to those without obesity. ${ }^{14,18,23,24}$ Further, kidney transplantation in patients with obesity provides a survival benefit compared to long-term dialysis, ${ }^{6,14,16}$ with one study finding that the mortality rate for patients with obesity who underwent transplantation was half that of those remaining on the wait list. ${ }^{25}$

Kidney transplant professionals (i.e., nephrologists, surgeons, nurse coordinators, social workers, pharmacists) involved in the transplantation referral and patient selection processes are the gatekeepers to kidney transplantation. Their knowledge and interpretation of the current evidence related to outcomes for kidney transplant recipients with obesity thereby influences clinical decision-making, and ultimately, patient selection for kidney transplantation. Therefore, the primary purpose of this study was to explore the attitudes of kidney transplant professionals regarding BMI-related patient selection criteria for kidney transplantation.

\section{Materials and Methods}

\section{Setting and Participant Sample}

Trained members of the research team conducted brief ( $<10$ minute) in-person, intercept interviews (i.e., the interviews were conducted onsite, spontaneously, without prior arrangement with the participants ${ }^{26}$ ) with a convenience sample of kidney transplant professionals attending the 2016 American Transplant Congress (ATC) in Boston, Massachusetts. The ATC is an annual meeting providing the most current information in the field of transplantation to physicians, surgeons, nurses, and other transplant professionals. In all, 277 (33.9\%) kidney transplant professionals were approached at the conference entrance and verbally invited to participate by two trained research assistants on three consecutive days during the conference. Potential participants were screened for eligibility with a single question asking whether they worked in the field of kidney transplantation at the time of the interview (see Appendix for screening question and full interview guide). All eligible participants $(\mathrm{N}=94)$ provided verbal consent to be surveyed and audio-recorded for research purposes. The Temple University Institutional Review Board deemed the study exempt. 


\section{Measurement}

Eligible participants answered a series of 14 open- and closed-ended questions about obesity and kidney transplant eligibility, and weight-related policies for patient selection at their respective transplant centers. Specifically, participants were asked to provide their opinions about kidney transplantation for patients with class 1 or classes 2 or 3 obesity using two open-ended questions. Participants were then asked to indicate if patients with class 1 obesity or classes 2 or 3 obesity should be eligible to receive a kidney transplant, and a maximum BMI limit for which they would still consider a patient eligible for kidney transplantation. Finally, participants were asked about their knowledge of any policies regarding BMI and kidney transplant eligibility at their respective transplant centers, and whether participants agreed with those policies. All interviews were audio-recorded and transcribed verbatim by trained research assistants; a subset of 20 transcripts were reviewed for transcription accuracy. Demographic information on respondents' role, gender, age, and race was also collected.

\section{Data Analysis}

Transcripts of open-ended responses were uploaded to MAXQDA (Version 12; VERBI software), a qualitative data analysis software, for content analysis. ${ }^{27}$ Initial coding categories were derived deductively from the literature and the questions posed during the interview, with additional codes emerging inductively through review of participant responses. ${ }^{28}$ Intercoder reliability of at least 80 percent agreement was achieved before two trained research assistants independently assigned specific codes to capture the thematic content of the response. Further disagreements in coding application were resolved by discussion. Descriptive statistics were used to summarize each quantitative variable, with means and standard deviations for continuous variables and frequencies and percentages for categorical variables. IBM SPSS Statistics for Windows (Version 24.0; Armonk, NY, USA) was used for all quantitative analyses.

\section{Results}

\section{Participant Demographics}

The sample included $29(31.5 \%)$ transplant nephrologists, $11(12.0 \%)$ transplant surgeons, 7 $(7.6 \%)$ nurse coordinators, 14 pharmacists $(15.2 \%)$, and 4 administrators $(4.3 \%)$; the remainder were other program staff (e.g., medical and surgical residents and fellows, etc.). The majority of those interviewed were female $(66.7 \%)$ and White $(68.9 \%)$, and the mean age was $40.6 \pm 10.4$ (see Table 1). 
Table 1. Participant Demographics

Demographic Characteristic (N=94)

$\begin{array}{ll}\begin{array}{l}\text { Age, Mean } \pm \text { SD } \\ \text { Sex, Count (\%) }\end{array} & 40.6 \pm 10.4 \\ \text { Female } & 60(66.7) \\ \text { Race/Ethnicity, Count (\%) } & \\ \text { White } & 62(68.9) \\ \text { Asian } & 17(18.9) \\ \text { Black/African American } & 5(5.6) \\ \text { Other } & 6(6.7) \\ \text { Role, Count (\%) } & \\ \text { Transplant Nephrologist } & 29(31.5) \\ \text { Transplant Surgeon } & 11(12.0) \\ \text { Pharmacist } & 14(15.2) \\ \text { Transplant Nurse Coordinator } & 7(7.6) \\ \text { Transplant Administrator } & 4(4.3) \\ \text { Other* } & 27(29.3)\end{array}$

Note: Values may not sum to $100 \%$ due to missing data. * Other roles included HLA staff, medical and surgical residents and fellows, data analysts, nurse practitioners, and researchers

\section{Class I Obesity and Patient Eligibility for Kidney Transplantation}

The majority of participants (88.0\%) indicated that patients with class 1 obesity (i.e., BMI between 30 and $<35 \mathrm{~kg} / \mathrm{m}^{2}$ ) should be eligible to receive a kidney transplant (see Table 2). Coding of the open-ended responses to participants' attitudes towards kidney transplantation for patients with obesity revealed ten themes (see Table 3). A majority of responses indicated that obesity alone is not a contraindication to kidney transplantation (57.0\%); few responses cited obesity as an absolute contraindication to kidney transplantation (3.2\%). Few participants also indicated that they would advise patients to pursue weight loss or bariatric surgery prior to kidney transplantation (5.4\%). For example, one respondent remarked, "... I think those patients may benefit more from bariatric surgery referral and then we'll consider if they don't go or if they lose some weight..." [Participant 1002], and another noted, "They [patients] would be referred to get bariatric surgery and lower BMI so they can have better outcomes" [Participant 2027]. A minority of participants (15.0\%) stated that kidney transplant eligibility based on BMI should be determined individually: “...it always depends on the patient, it always has to be - you bave to always take a look at all the factors involvedcomorbidities, social support, psychosocial, all those issues before you make any decision about any patient..." [Participant 1003]. 
A few individuals suggested that BMI alone is a poor indicator of success with kidney transplantation (4.3\%). For instance, one respondent commented, "A lot of these people tend to bave higher weights and higher muscle mass and I think we are limiting our population of potential good candidates based on BMI," [Participant 1007]. Similarly, another stated, "...you have to look at comorbidities and assess all the things you would do for any other transplant, you know, are they going to be able to get their medications, are they going to go to their follow up appointments, I don't think that BMI alone should qualify or disqualify - initially..." [Participant 1027]. Participants also remarked on the benefits of transplantation afforded to patients compared to indefinite dialysis: "...their outcomes are better than dialysis so it should be offered with informed consent of some of the increased complication rates." "Participant 1032]. This was a common sentiment, even when challenges were acknowledged: "It's a challenge because there's a very high risk of wound infections in these patients and they just don't tend to do as well as the rest, but... if you don't transplant them, these patients have no other options."

Table 2. Perceptions of Patient Eligibility by BMI

\begin{tabular}{lll}
\hline \multirow{2}{*}{ Eligible for Kidney Transplant } & BMI & \\
\cline { 2 - 3 } & $\mathbf{3 0 - 3 4}$ & $\mathbf{3 5}$ \\
\hline Yes & $81(88.0)$ & $31(33.7)$ \\
No & $2(2.2)$ & $9(9.8)$ \\
Maybe/It Depends & $9(9.8)$ & $52(56.5)$ \\
Note: Values expressed as count (percent). & \\
\hline
\end{tabular}

Table 3. Attitudes about Patient Eligibility by BMI

\begin{tabular}{|c|c|c|c|}
\hline \multicolumn{2}{|c|}{ Class 1 Obesity (BMI $\left.30-<35 \mathrm{~kg} / \mathrm{m}^{2}\right)$} & \multicolumn{2}{|c|}{ Classes 2 and 3 Obesity (BMI $\left.\geq 35 \mathrm{~kg} / \mathrm{m}^{2}\right)$} \\
\hline $\begin{array}{l}\text { Would transplant }- \text { not } a \\
\text { contraindication }\end{array}$ & $53(57.0)$ & Depends on patient & $38(26.4)$ \\
\hline Depends on patient & $14(15.0)$ & $\begin{array}{l}\text { Would not transplant - absolute } \\
\text { contraindication }\end{array}$ & $32(22.2)$ \\
\hline Another risk to consider & $7(7.5)$ & $\begin{array}{l}\text { More risk/complications -technically } \\
\text { challenging }\end{array}$ & $27(18.7)$ \\
\hline Advise weight loss/bariatric surgery & $5(5.4)$ & Advise weight loss/bariatric surgery & $22(15.3)$ \\
\hline $\begin{array}{l}\text { BMI is poor indicator - needs } \\
\text { reexamination }\end{array}$ & $4(4.3)$ & Would/should transplant & $12(8.3)$ \\
\hline $\begin{array}{l}\text { Would not transplant - absolute } \\
\text { contraindication }\end{array}$ & $3(3.2)$ & Better to transplant - survival benefit & $7(4.9)$ \\
\hline $\begin{array}{l}\text { Have similar outcomes to other } \\
\text { patients }\end{array}$ & $3(3.2)$ & $\begin{array}{l}\mathrm{BMI} \text { is poor indicator }- \text { needs } \\
\text { reexamination }\end{array}$ & $3(2.1)$ \\
\hline Better to transplant - survival benefit & $2(2.2)$ & Not enough evidence - unsure & $2(1.4)$ \\
\hline May contribute to disparities & $1(1.1)$ & Surgeon preference & $1(0.7)$ \\
\hline Unsure & $1(1.1)$ & May contribute to disparities & $1(0.7)$ \\
\hline Total Coded Segments & 93 & Total Coded Segments & 144 \\
\hline $\begin{array}{l}\text { Note: Values expressed as } \mathrm{fr} \\
\text { of the transcripts with corre }\end{array}$ & ercer & segments refers to the specific seg & \\
\hline
\end{tabular}




\section{Classes II or III Obesity and Patient Eligibility for Kidney Transplantation}

When asked about transplant eligibility for patients with classes 2 or 3 obesity (BMI $\geq 35 \mathrm{~kg} / \mathrm{m}^{2}$ ), far fewer participants were unreservedly willing to consider these patients as transplant candidates (33.7\%), with just over half of the sample (56.5\%) indicating that it would depend on other factors (see Tables $2 \& 3)$. Twenty-two percent $(22.2 \%)$ considered classes 2 or 3 obesity an absolute contraindication to kidney transplant. However, over a quarter of respondents $(26.4 \%)$ indicated that the determination depends on the individual patient's entire clinical and psychosocial presentation, not merely the patient's BMI. One participant claimed, "I would say you have to take into account other factors because BMI itself doesn't mean much, you bave to look at them in person to make that decision" [Participant 1020]. Respondents (18.7\%) also acknowledged that kidney transplant surgery among patients with more severe obesity can be technically challenging and has an increased risk of postoperative complications: "I think these people tend to have higher complication rates, more wound complications, DVTs, pulmonary complications... and they tend to have more comorbidities so I'm a little more cautious, but I do transplant them" [Participant 807]. For patients with severe obesity, $15 \%$ of the professionals surveyed advised weight loss or bariatric surgery prior to kidney transplantation.

Table 4. Knowledge of and Agreement with Transplant Center's BMI/Weight Policy

\begin{tabular}{ll|lc}
\hline Knowledge of Policy & & Agreement with Policy* \\
\hline Center has policy & $79(86.8)$ & Agrees & $69(87.3)$ \\
Center has no policy & $7(7.7)$ & Disagrees & $10(12.7)$ \\
Unsure & $5(5.5)$ & & \\
Note: $*$ Only individuals acknowledging awareness of policy included in analysis $(\mathrm{n}=79)$. \\
\hline
\end{tabular}

\section{Knowledge of and Agreement with Transplant Center BMI Policy}

The majority of participants (86.8\%) were aware of a BMI-specific kidney transplant patient selection criteria policy at their respective transplant centers (see Table 4). Of the participants aware of a BMI-specific patient selection policy, most were in agreement with the BMI parameters stated in the current policy $(87.3 \%$ ) (see Table 4). However, transplant professionals suggested a mean maximum BMI limit for kidney transplantation that was 2.3 points higher than the mean maximum BMI limit detailed in the transplant centers' policies. More specifically, the average maximum BMI for which participants would still consider patients for kidney transplantation was $38.6 \pm 3.1 \mathrm{~kg} / \mathrm{m}^{2}$ while the average maximum BMI stipulated recalled in transplant centers' policies was $36.3 \pm 3.1 \mathrm{~kg} / \mathrm{m}^{2}$ (see Table 5). The highest suggested BMI was 45.0, compared to a maximum BMI limit of 40.0 among the transplant center policies (see Table $5)$.

Table 5. Self-Selected and Transplant Center Policy Patient BMI Maximum

\begin{tabular}{lll}
\hline Source & Mean \pm SD & Range \\
\hline Transplant Professionals & $38.6 \pm 3.1$ & $30.0-45.0$ \\
Transplant Center Policy & $36.3 \pm 3.1$ & $30.0-40.0$ \\
\hline
\end{tabular}




\section{Discussion}

The findings of this study suggest that kidney transplant professionals have a nuanced understanding of the issue of obesity and kidney transplant eligibility. Participants in this study endorse assessment of the specific clinical and psychosocial circumstance of each individual patient, over a specific BMI cutoff, when making a determination for transplant eligibility. This is consistent with the official stance of the Renal Association, which concluded that obesity is not an absolute contraindication to transplantation, and recommends rigorous screening for cardiovascular disease, and individual assessments of transplant eligibility rather than a maximum BMI limit. ${ }^{29}$ Nevertheless, being classified as having obesity can impede attaining an active status on the kidney transplant waiting list and can significantly increase wait time. ${ }^{30}$ In 2012, 1096 $(5.6 \%)$ of transplant candidates classified as inactive on the transplant waiting list after their initial listing were labeled as such secondary to their BMI. ${ }^{31}$ Among transplant candidates with obesity who were categorized as inactive for weight-related reasons, just half ever achieved active status on the waiting list, and another $15 \%$ died before reaching active status. ${ }^{22}$ Further, investigations of access to transplantation by weight found that as BMI increased, the likelihood of receiving a transplant decreased, and the risk of being bypassed once an available kidney was identified also increased. ${ }^{32}$

The American Society for Transplantation recommends that potential transplant candidates receive weight loss therapy to achieve a goal BMI $<30 \mathrm{~kg} / \mathrm{m}^{2}$ prior to transplantation. ${ }^{33}$ Those individuals would be considered overweight rather than obese. This suggestion was cited by several study participants, who report advising patients with obesity, particularly patients with a BMI above 35, to engage in weight loss interventions, such as lifestyle modification (which typically includes caloric restriction, increased physical activity, and instruction in behavioral modification), pharmacotherapy, or bariatric surgery prior to accessing the transplant wait list. However, achieving sustained, significant weight loss while on dialysis can be difficult. Patients receiving dialysis, and following the dietary restrictions that accompany dialysis, may experience fatigue, declines in cognitive function, decreased muscle strength and endurance, as well as increased frailty. ${ }^{34}{ }^{37}$ In comparison, more aggressive weight-reduction approaches such as bariatric surgery are effective at reducing BMI in transplant candidates ${ }^{38}$ Transplant centers likely do not have the resources or expertise to provide weight loss interventions to their patients. While many medical centers and hospitals may have multidisciplinary weight loss programs that offer the range of treatments, end stage renal disease likely makes active participation challenging for patients. Furthermore, weight loss treatment is not part of the universal insurance mandate at this time. While the Centers for Medicare and Medicaid Services (CMS) began to provide coverage for medically supervised weight loss several years ago, only a limited number of physicians (primarily obesity medicine specialists) routinely offer this treatment to patients. ${ }^{39}$ Finally, the modest weight losses of $5-7 \%$ of initial body weight typically seen with non-surgical weight loss treatment have not been shown to improve transplant outcomes. ${ }^{30,31}$ Thus, the appropriateness of mandating weight loss for patients to qualify for transplantation may not be scientifically justified at this time.

CMS, which helps to oversee transplantation in the U.S., mandates that kidney transplant centers have patient selection criteria policies that identify indications and contraindications to kidney 
transplantation. ${ }^{40}$ Transplant centers are expected to adhere to their patient selection policies; however, any diversion from the policy can be documented with an acceptable justification. ${ }^{40}$ In our study, participants self-selected a mean maximum BMI limit for kidney transplant recipients that was 2.3 points higher than the mean maximum BMI limit reported in their respective transplant centers' policies. This finding suggests that transplant professionals are more willing to accept patients with higher BMIs and may be able to advocate within their programs for access to transplantation for a wider range of patients. This warrants further consideration, as it remains unclear if the inherent flexibility of patient selection criteria policies is well-known. Dialysis centers often use the transplant eligibility policies from local transplant centers to guide their transplant referral process for dialysis patients. Patients with higher BMIs may be discouraged from entering the transplantation evaluation process, and subsequently will not receive the medically managed weight loss support that may allow them to meet the kidney transplant eligibility criteria of their respective transplant centers. Some researchers have also suggested that a bias against considering high-risk candidates for kidney transplantation may exist among providers who may opt for a more conservative patient selection approach to accommodate regulatory agencies and payer sources. ${ }^{32}$

This study's findings should be interpreted in the context of its limitations. Namely, the convenience sample of kidney transplant professionals that attended the 2016 ATC is subject to selection bias, thus limiting the generalizability of the findings. In addition, information regarding the geographic location of participants or their respective transplant centers was not collected. Finally, participants' may not have accurately recalled their transplant program's BMI limits; patient selection policies were not collected for verification. Future studies should obtain these data points and utilize random sampling methods to increase the generalizability of their results. However, these findings serve as a critical initial step for understanding kidney transplant professionals' perceptions about patients with obesity and their kidney transplant eligibility. Moreover, future studies should include an analysis of kidney transplant centers' patient selection criteria policies to identify common practices and conduct an in-depth examination of outcomes among kidney transplant recipients with obesity.

The persistence of the supply and demand disparity in kidney transplantation ensures that patient selection criteria will remain in use for the foreseeable future. Therefore, it is essential to critically examine the policies and practices utilized in patient selection by transplant professionals and transplant centers, to ensure that these scarce resources are allocated in an unbiased and just manner, based on existing clinical evidence.

\section{Disclosures and Conflicts of Interest}

The authors have no conflicts to disclose.

\section{References}

1. Organ Procurement and Transplantation Network. Data Report, 2020. 
2. Barker CF, Markmann JF. Historical overview of transplantation. Cold Spring Harb Perspect Med. 2013;3(4). doi:10.1101/cshperspect.a014977.

3. Hales CM, Carroll MD, Fryar CD, Ogden CL. Prevalence of obesity and severe obesity among adults: United States, 2017-2018. NCHS Data Brief, No. 360, February 2020.

4. Yang L, Colditz GA. Prevalence of overweight and obesity in the United States, 20072012. JAMA Intern Med. 2015;175(8):1412-1413. doi:10.1001/jamainternmed.2015.2405.

5. Kramer HJ. Increasing Body Mass Index and Obesity in the Incident ESRD Population. J Am Soc Nephrol. 2006;17(5):1453-1459. doi:10.1681/ASN.2005111241.

6. Johansen KL. Obesity and body composition for transplant wait-list candidacy challenging or maintaining the BMI limits? J Ren Nutr. 2013;23(3):207-209. doi:10.1053/j.jrn.2013.02.005.

7. Centers for Disease Control and Prevention. Defining adult overweight and obesity. Centers for Disease Control and Prevention. doi:https://www.cdc.gov/obesity/adult/defining.html.

8. Gill JS, Lan J, Dong J, et al. The Survival Benefit of Kidney Transplantation in Obese Patients. Am J Transplant. 2013;13(8):2083-2090. doi:10.1111/ajt.12331.

9. Curran SP, Famure O, Li Y, Kim SJ. Increased recipient body mass index is associated with acute rejection and other adverse outcomes after kidney transplantation. Transplantation. 2014;97(1):64-70. doi:10.1097/TP.0b013e3182a688a4.

10. Furriel F, Parada B, Campos L, et al. Pretransplantation overweight and obesity: Does it really affect kidney transplantation outcomes? In: Transplantation Proceedings. Vol 43. ; 2011:95-99. doi:10.1016/j.transproceed.2010.12.027.

11. Gore JL, Pham PT, Danovitch GM, et al. Obesity and outcome following renal transplantation. Am J Transplant. 2006;6(2):357-363. doi:10.1111/j.16006143.2005.01198.x.

12. Molnar MZ, Kovesdy CP, Mucsi I, et al. Higher recipient body mass index is associated with post-transplant delayed kidney graft function. Kidney Int. 2011;80(2):218-224. doi:10.1038/ki.2011.114.

13. Lafranca JA, IJermans JNM, Betjes MGH, Dor FJMF. Body mass index and outcome in renal transplant recipients: a systematic review and meta-analysis. BMC Med. 2015;13:111. doi:10.1186/s12916-015-0340-5.

14. Bennett WM, Mcevoy KM, Henell KR, Pidikiti S, Douzdjian V, Batiuk T. Kidney transplantation in the morbidly obese: Complicated but still better than dialysis. Clin Transplant. 2011;25:401-405. doi:10.1111/j.1399-0012.2010.01328.x.

15. Johnson DW, Isbel NM, Brown AM, et al. The effect of obesity on renal transplant outcomes. Transplantation. 2002;74:675-681. doi:10.1097/01.tp.0000019424.37813.26.

16. Marks WH, Florence LS, Chapman PH, Precht AF, Perkinson DT. Morbid obesity is not a contraindication to kidney transplantation. In: American Journal of Surgery. Vol 187. ; 2004:635-638. doi:10.1016/j.amjsurg.2004.01.015.

17. Singh D, Lawen J, Alkhudair W. Does pretransplant obesity affect the outcome in kidney transplant recipients? In: Transplantation Proceedings. Vol 37. ; 2005:717-720. doi:10.1016/j.transproceed.2004.12.033.

18. Lynch RJ, Ranney DN, Shijie C, Lee DS, Samala N, Englesbe MJ. Obesity, surgical site infection, and outcome following renal transplantation. Ann Surg. 2009;250(6):1014-1020. doi:10.1097/SLA.0b013e3181b4ee9a. 
19. Naik AS, Sakhuja A, Cibrik DM, Ojo AO, Samaniego-Picota MD, Lentine KL. The Impact of Obesity on Allograft Failure After Kidney Transplantation: A Competing Risks Analysis. Transplantation. 2016;100(9):1963-1969. doi:10.1097/TP.0000000000000983.

20. Lentine, KL; Rocca-Rey, LA; Bacchi, G; Wasi, N; Schmitz, L; Salvalaggio, PR; Abbott, KC; Schnitzler, MA; Neri, L; Brennan D. Obesity and cardiac risk after kidney transplantation: experience at one center and comprehensive literature review. Transplantation. 2008;86(2):303-312.

21. Gusukuma LW, Harada KM, Baptista APM, et al. Outcomes in obese kidney transplant recipients. Transplant Proc. 2014;46(10):3416-3419. doi:10.1016/j.transproceed.2014.09.112.

22. Huang E, Shye M, Elashoff D, Mehrnia A, Bunnapradist S. Incidence of Conversion to Active Waitlist Status Among Temporarily Inactive Obese Renal Transplant Candidates. Transplantation. 2014;0(2):1-10. doi:10.1097/TP.0000000000000037.

23. Bardonnaud N, Pillot P, Lillaz J, et al. Outcomes of renal transplantation in obese recipients. In: Transplantation Proceedings. Vol 44. ; 2012:2787-2791. doi:10.1016/j.transproceed.2012.09.031.

24. Ditonno P, Lucarelli G, Impedovo S V., et al. Obesity in kidney transplantation affects renal function but not graft and patient survival. In: Transplantation Proceedings. Vol 43. ; 2011:367-372. doi:10.1016/j.transproceed.2010.12.022.

25. Glanton CW, Kao T-C, Cruess D, Agodoa LYC, Abbott KC. Impact of renal transplantation on survival in end-stage renal disease patients with elevated body mass index. Kidney Int. 2003;63(2):647-653. doi:10.1046/j.1523-1755.2003.00761.x.

26. Rea LM, Parker RA. Designing and Conducting Survey Research: A Comprehensive Guide.; 2005.

27. Hsieh H-F, Shannon SE. Three Approaches to Qualitative Content Analysis. Qual Health Res. 2005;15:1277-1288. doi:10.1177/1049732305276687.

28. Zhang Y, Wildemuth BM. Qualitative Analysis of Content. Appl Soc Res Methods to Quest Inf Libr Sci. 2009:421. doi:10.1002/hbm.20661.

29. Dudley C, Harden P. Renal association clinical practice guidelines on the assessment of the potential kidney transplant recipient. Nephron Cinical Pract. 2011;118:C209.

30. Huang E, Bunnapradist S. Pre-transplant weight loss and survival after kidney transplantation. Am J Nephrol. 2015;41(6):448-455. doi:10.1159/000437341.

31. Matas AJ, Smith JM, Skeans MA, et al. OPTN/SRTR 2012 Annual Data Report: Kidney. Am J Transplant. 2014;14(SUPPL. 1):11-44. doi:10.1111/ajt.12579.

32. Segev DL, Simpkins CE, Thompson RE, Locke JE, Warren DS, Montgomery R a. Obesity impacts access to kidney transplantation. J Am Soc Nephrol. 2008;19:349-355. doi:10.1681/ASN.2007050610.

33. Kasiske, BL; Cangro, CB; Hariharan, S; Hricik, DE; Kerman, RH; Roth, D; Rush, DN; Vasquez, MA; Weir MAS of T. The evaluation of renal transplantation cnadidates: clinical practice guidelines. Am J Transplant. 2001;Supp 1(2):5-95.

34. Delgado C, Johansen KL. Barriers to exercise participation among dialysis patients. Nephrol Dial Transplant. 2012;27(3):1152-1157. doi:10.1093/ndt/gfr404.

35. Jhamb, M; McNulty, ML; Ingalsbe, G; Childers, JW; Schell, J; Conroy, MB; Forman, DE; Hergenroeder, A; Dew M. Knowledge, barriers and facilitators of exercise in dialysis patients: a qualitative stud of patients, staff and nephrologists. BMC Nephrol. 2016;17(1):192. 
36. McAdams-Demarco MA, Tan J, Salter ML, et al. Frailty and cognitive function in incident hemodialysis patients. Clin J Am Soc Nephrol. 2015;10(12):2181-2189. doi:10.2215/CJN.01960215.

37. McAdams-Demarco MA, Law A, Salter ML, et al. Frailty as a novel predictor of mortality and hospitalization in individuals of all ages undergoing hemodialysis. J Am Geriatr Soc. 2013;61(6):896-901. doi:10.1111/jgs.12266.

38. Freeman CM, Woodle ES, Shi J, et al. Addressing morbid obesity as a barrier to renal transplantation with laparoscopic sleeve gastrectomy. Am J Transplant. 2015;15(5):13601368. doi:10.1111/ajt.13116.

39. Yarborough CM, Brethauer S, Burton WN, et al. Obesity in the Workplace. J Occup Environ Med. 2018;60(1):97-107. doi:10.1097/JOM.0000000000001220.

40. Centers for Medicare and Medicaid Services. Organ transplant interpretive guidelines. https://www.cms.gov/Medicare/Provider-Enrollment-and-

Certification/SurveyCertificationGenInfo/downloads/SCLetter08-25.pdf. Published 2008.

\section{Statement of Contributions}

Heather Gardiner, Salini Inaganti and Chidera Agu participated in research design. Salini Inaganti and Chidera Agu participated in the performance of the research. Heather Gardiner and Megan Urbanski participated in data analysis. All authors participated in the writing of the paper.

\section{ORCID IDs}

Chidera Agu: https://orcid.org/0000-0003-2585-7118

David Sarwer: https://orcid.org/0000-0003-1033-5528

Heather Gardiner: https://orcid.org/0000-0003-2017-991X 